\title{
Cost effectiveness of strategies to combat neuropsychiatric conditions in sub-Saharan Africa and South East Asia: mathematical modelling study
}

\author{
(c) (1) (8) OPEN ACCESS
}

\author{
Dan Chisholm health economist ${ }^{12}$, Shekhar Saxena director ${ }^{2}$
}

${ }^{1}$ Department of Health Systems Financing, World Health Organization, 1211 Geneva, Switzerland; ${ }^{2}$ Department of Mental Health and Substance Abuse, World Health Organization, Geneva, Switzerland

\begin{abstract}
Objective To assess the comparative costs and effects of interventions to combat five neuropsychiatric conditions (schizophrenia, bipolar disorder, depression, epilepsy, and heavy alcohol use).

Design Cost effectiveness analysis based on an epidemiological model. Setting Two epidemiologically defined World Health Organization sub-regions of the world: countries in sub-Saharan Africa with very high adult and high child mortality (AfrE); and countries in South East Asia with high adult and high child mortality (SearD).
\end{abstract}

Data sources Published studies, costing databases.

Main outcome measures Cost per capita and cost per disability adjusted life year (DALY) averted, expressed in international dollars (\$Int) for the year 2005

Results Across 44 assessed intervention strategies for the five neuropsychiatric conditions, cost effectiveness values differed by as much as two orders of magnitude (from \$Int100-250 to \$Int10 000-25 000 for a year of healthy life gained). In both sub-regions, inpatient based treatment of schizophrenia with newer antipsychotic drugs was the most costly and least cost effective strategy. The most cost effective strategies in the African sub-region related to population based alcohol control, while in the South East Asian sub-region the most cost effective intervention was drug treatment of epilepsy in primary care. The cumulative cost per capita of the most cost effective set of interventions covering all five conditions was estimated at \$Int4.90-5.70. This package comprises interventions for epilepsy (older first line antiepileptic drugs); depression (generically produced newer antidepressants and psychosocial treatment); bipolar disorder (mood stabiliser drug lithium); schizophrenia (neuroleptic antipsychotic drugs and psychosocial treatment); and heavy alcohol use (increased taxation and its enforcement, reduced access, and, in the African sub-region, advertising bans and brief advice to heavy drinkers in primary care).
Conclusions Reallocation of resources to cost effective intervention strategies would increase health gain, save money and help implement much needed expansion of services for neuropsychiatric conditions in low resource settings.

\section{Introduction}

Despite accounting for at least a quarter of total non-communicable disease burden, ill health resulting from mental, neurological, and substance use disorders remains a neglected and under-resourced element within healthcare systems in low and middle income countries. ${ }^{1}$ Many countries currently allocate less than $2 \%$, or even $1 \%$, of the health budget to the treatment and prevention of these disorders, with most funds typically directed towards the running costs of mental hospital services. ${ }^{2}$ The situation is particularly bleak in low income countries, where on average there is one psychiatrist per 1.7 million inhabitants and one psychiatric inpatient bed per 42000 inhabitants. ${ }^{2}$ Unsurprisingly, there is a large treatment gap for neuropsychiatric conditions in developing regions ${ }^{3}$; for epilepsy, the treatment gap has been put at $56 \%$, while, for people with severe mental disorders, a large multi-country survey showed that $76-85 \%$ did not receive any treatment in the previous 12 months. ${ }^{4}$

The current state of mental healthcare in resource constrained countries raises questions not only about the adequacy and distribution of resources for treating and preventing disorders, but also about the efficiency with which the resources are used. By simultaneously examining the cost effectiveness of a core set of interventions across a range of key neuropsychiatric conditions, this paper primarily addresses the question of efficiency. In so doing, it also establishes what level of resources would be required to implement a combined set of cost effective 
strategies for the conditions scaled up for country-wide coverage. Such information can contribute to renewed efforts to scale up mental health services in low and middle income countries. $^{5}$

\section{Methods}

\section{Setting}

In line with other papers in this series, results are provided for two epidemiologically defined World Health Organization sub-regions of the world: AfrE, which includes countries in the WHO sub-Saharan African region with high child and very high adult mortality (such as Kenya and Tanzania); and SearD, which includes countries in the WHO South East Asia region with high child and adult mortality (such as India and Nepal) (see appendix A on bmj.com for a full list of countries within these sub-regions).

\section{Selection of disorders and interventions}

Economic evaluation was carried out for a range of interventions relating to five prominent contributors to the global burden of disease. Schizophrenia, bipolar affective disorder, and depression each contribute at least $1 \%$ to the global burden of disease,${ }^{6}$ as do alcohol use disorders, but in this case we extended the scope to the broader and more burdensome entity of heavy alcohol use (as a risk factor for neuropsychiatric and other diseases, defined in terms of an average intake of $>40 \mathrm{~g}$ of pure alcohol daily for men and $>20 \mathrm{~g}$ for women). ${ }^{7}$ There is substantial evidence for the effectiveness of interventions for these conditions. ${ }^{89}$ Analysis was also undertaken for epilepsy, a common and highly treatable neurological disorder accounting for $0.5 \%$ of the global burden of disease. ${ }^{10}$

Intervention analysis was not performed for other conditions that, despite their potential inclusion within a comprehensive mental health programme, ${ }^{5}$ currently impose less disease burden on populations or offer more limited scope for cost effective prevention or treatment (such as anxiety disorders, dementia, and developmental disorders).

Assessed interventions for the selected conditions cover both individual and population based strategies, and were evaluated at varying levels of feasible target population coverage (table $1 \Downarrow$ ). All conditions and interventions are included in the WHO mhGAP Intervention Guide ${ }^{11}$ or, in the case of heavy alcohol use, represent central components of the WHO Global Strategy to Reduce the Harmful Use of Alcohol. ${ }^{12}$

\section{Estimation of intervention effectiveness}

Intervention analysis for each of the conditions followed standard WHO-CHOICE methods, adopting an epidemiological, population based approach to assessing health outcomes (see general appendix on bmj.com). ${ }^{13}{ }^{14} \mathrm{~A}$ first analytical step was to generate a profile of the prevailing epidemiological situation for each condition in terms of incidence, prevalence, remission, and case fatality, as well as the average level of associated disability (on a $0-1$ scale, where $0=$ no disability). These parameters were derived from the Global Burden of Disease ${ }^{6}$ or, in the case of heavy alcohol use, the Comparative Quantification of Health Risks for 2004. ${ }^{7}$ These estimates are in turn based on representative country surveys that have been undertaken in different sub-regions of the world (see appendix A on bmj.com).

Observed epidemiological rates and disability weights were entered into a generic state transition model (PopMod) ${ }^{14}$ in order to establish the total amount of healthy life years experienced over the 100 year lifetime of a defined population - in this case whole WHO sub-regions. The model was then re-run to identify the difference in healthy years lived by the population as a result of adding intervention effects (expressed as percentage change to one or more of the model inputs for a period of 10 years, such as an increase in the rate of remission or a reduction in average disability level). In this way, we were able to compare the total number of healthy years lived-equivalent to the number of disability adjusted life years (DALYs) averted-with and without intervention. In line with WHO burden of disease estimation ${ }^{67}$ and standard WHO-CHOICE methods, ${ }^{13}{ }^{14}$ DALYs averted were discounted (at 3\%) and weighted for age (see also general appendix on bmj.com).

Sources of data for intervention efficacy and effectiveness included meta-analyses, systematic reviews, and individual clinical trials reported in the international literature, and are described in detail elsewhere. ${ }^{15-19}$ Table $1 \Downarrow$ summarises efficacy estimates for the interventions (a more detailed review of data sources for the efficacy of each intervention is presented in appendix A on bmj.com). Target treatment coverage were set at $80 \%$ for schizophrenia and epilepsy, $50 \%$ for affective disorders, and $30 \%$ for heavy alcohol use. These were considered appropriate based on the severity of presenting symptoms and established challenges of case identification and health seeking behaviour for the latter conditions. Adherence rates for long term therapies in the real world often fall to as low as 50\% (compared with at least $70 \%$ in most clinical trials), ${ }^{20}$ so, with the exception of inpatient treatment for serious mental disorders and brief interventions for heavy drinkers, we adjusted reported adherence from efficacy trials downwards by a factor of two thirds in order to better approximate real world effectiveness.

\section{Estimation of intervention costs}

An "ingredients" approach to the costing of health interventions was used, ${ }^{13}{ }^{14}$ requiring separate identification and valuation of the quantity of all resource inputs needed (such as numbers of staff) and the price or unit cost of those resource inputs (such as salary of a nurse). For resource quantities at the patient level (such as hospital inpatient days, outpatient visits, drugs, laboratory tests), information sources include data from economic evaluations and a multinational Delphi consensus study. ${ }^{21}$ Resource use profiles are described at appendix A on bmj.com. Unit costs associated with these items of service use have been estimated for the year 2005 for each WHO reporting sub-region, based on econometric analysis of a multinational dataset, using gross domestic product (GDP) per capita (plus other explanatory variables) as predictors (www.who.int/choice/ costs). In addition, programme costs were computed, which are resources used at a level above that of the patient or providing facility; these include central planning, policy formulation or development, and administration functions, as well as resources devoted to training staff or enforcing laws.

Costs for the 10 year implementation period were discounted at 3\% and expressed in international dollars (\$Int), which adjust for differences in the relative price and purchasing power of countries and thereby facilitate comparison across regions (that is, \$Int1 buys the same quantity of healthcare resources in Kenya or India as it does in the United States; for the African and Asian sub-regions used in this analysis, \$Int 1 is worth US\$0.44 and US\$0.32 respectively).

\section{Uncertainty analysis}

In order to assess the inherent uncertainty around (point) estimates of total intervention costs and health effects, a number 
of steps were carried out. Firstly, results were placed on a logarithmic scale in order to ascertain order of magnitude differences in cost effectiveness (for example, \$Int10-100v \$Int100-1000 per DALY averted). Secondly, results were categorised according to a defined set of cost effectiveness thresholds: WHO-CHOICE denotes as "cost effective" an intervention that produces a healthy year of life for less than three times the GDP per capita, and as "very cost effective" an intervention that produces a healthy year of life for less than GDP per capita. Finally, for the subset of intervention strategies that were dominant over others for the condition in question - that is, those that are less costly or more effective, or both, than other less efficient interventions-baseline data (together with coefficients of variation amounting to 15-25\% above and below baseline values) were entered into an analytical software package (MCLeague), which performs a probabilistic uncertainty analysis using Monte Carlo simulation (1000 runs were made using a truncated normal distribution). ${ }^{14}$

\section{Results}

For a standardised population of one million people, table $2 \Downarrow$ shows the costs, effects, and cost effectiveness of 44 individual or combined interventions for the selected conditions in the two sub-regions considered. These three sets of information are also shown graphically in figures $1 \Downarrow$ and $2 \Downarrow$, which use a logarithmic scale to display the wide variations in costs or effects (diagonal lines show successive order of magnitude differences between interventions, such as \$Int100 $v$ \$nt1000 per DALY averted).

For sub-Saharan Africa (fig $1 \Downarrow$ ), average cost effectiveness ratios diverge by as much as two orders of magnitude (from a little over \$Int 100 to more than \$Int10 000 per DALY averted), meaning that the most efficient interventions for this cluster of conditions (population based alcohol control policies) are 100 times more cost effective than the least efficient choices (hospital based treatment of schizophrenia with newer, atypical antipsychotic drugs). To illustrate, current or increased taxation on alcoholic drinks (coded as ALC-1, ALC-2, ALC-3 in table $2 \Downarrow$ ) is estimated to generate in the range of $1800-2000$ additional healthy life years per million population each year at a cost of \$Int240 000 (that is, \$Int0.24 per capita), whereas inpatient based treatment of schizophrenia with newer antipsychotics (without any psychosocial care and support, coded SCZ-6) is estimated to generate 200 healthy life years and costs nearly \$Int5 million (\$Int5 per capita). A far more cost effective approach to the treatment of schizophrenia and of bipolar affective disorder is to provide a community, outpatient based service and offer older (but no less effective) psychotropic drugs in conjunction with psychosocial treatments such as family therapy. With these interventions, health improvements become appreciably higher, the cost per capita decreases dramatically (to \$Int1), and average cost effectiveness ratios come down to \$Int2500 for schizophrenia (SCZ-3) and \$Int2750 for bipolar disorder (BIP-2). ${ }^{18}{ }^{19}$ This range of cost effectiveness is still 10 times higher than that found for antiepileptic drug treatment in primary care (EPI-1 and EPI-2), and three times greater than that for episodic treatment of depression in primary care with generic forms of newer antidepressants (DEP-2).

For South East Asia, results are similar to those for the African region, which reflects not only similarities in underlying rates of disease and outcome in the population but also input prices on the cost side. The key difference in the Asian sub-region relates to the relatively lower prevalence of heavy alcohol use, with the result that population based alcohol interventions are much less cost effective. Thus, implementation of alcohol taxation policies generates only a fraction of the health gain achieved in the African sub-region (70-90 DALYs averted per million population each year). As a result, it is treatment of depression that is expected to generate most health gain in the population, and treatment of epilepsy that represents the most cost effective use of resources in this setting.

The incremental ordering and selection of the various competing strategies in terms of their cost effectiveness are shown in figures $3 \Downarrow$ and $4 \Downarrow$, which show the order in which interventions would be successively chosen across the five conditions (and at what cumulative cost). Thus in the African sub-region, increasing the rate of tax on alcoholic drinks (by 50\%) would be the first from the 44 interventions considered since it has the lowest cost per standardised unit of outcome (compared with the situation of doing none of the interventions). The next most cost effective choices would be other population based alcohol

interventions_-enhanced tax enforcement activities and reduced access to retail outlets-followed by epilepsy treatment (initially at $50 \%$ coverage, and then expanding to $80 \%$ ). Successively less cost effective interventions for each of the conditions are subsequently included. At the point that the last disease is represented (schizophrenia), the cumulative cost per capita of implementing a cost effective set of health maximising interventions across this cluster of five conditions is estimated at \$Int5.70. A similar cumulative cost is estimated for SearD (\$Int4.90), but in this case epilepsy then depression treatments precede the inclusion of population based alcohol interventions.

Finally, by entering costs and effectiveness data into a stochastic uncertainty framework, it is possible to assess the impact of plausible levels of variability around reported point estimates. The graphical results presented in appendix B on bmj.com show that, even after allowing for this variability, the average cost effectiveness ratios of interventions addressing depression, epilepsy, and heavy alcohol use in the African sub-region continue to fall completely or largely below the "very cost effective" threshold of \$Int2000 per healthy life year gained, while the most efficient intervention for schizophrenia (SCZ-3) and bipolar disorder (BIP-1) predominantly fall within the "cost effective" threshold of $\$$ Int6000 per healthy life year gained. Similar results pertain to the South-East Asian sub-region, except that interventions aimed at combating heavy alcohol use largely fall outside the very cost effective threshold (but still within the cost effective threshold). The same logic would apply to incremental cost effectiveness ratios.

\section{Discussion}

\section{Key findings and implications}

By employing a consistent methodological approach, this sectoral analysis has been able to compare systematically the costs and health outcomes of a broad set of interventions for neuropsychiatric conditions that between them represent a substantial source of global disease burden. One use of such an exercise is to locate the relative position of these interventions within a wider cost effectiveness framework in the healthcare sector, as attempted in the final article of this series. ${ }^{22}$ In the current paper, the focus has not been to compare interventions for neuropsychiatric conditions with those for other non-communicable diseases but with each other-to determine which, from an efficiency perspective, have the most claim on resources for mental health. Such an exercise has not been undertaken before for low resource settings. Earlier cost effectiveness analyses focused on specific neuropsychiatric conditions ${ }^{15-19}$ and therefore did not allow for a broader 
consideration of the relative priorities to be given to competing conditions or intervention strategies.

The results show a wide range of the cost effectiveness of possible actions that could be undertaken in the two selected sub-regions in Africa and South East Asia, with the cost per year of healthy life varying from many multiples to just a fraction of average per capita income. Use of a per capita income threshold (around \$Int2000 in these two sub-regions) provides a convenient means for assessing the likely affordability of current or future investments, and the evidence presented here shows that there are plenty of candidates in the neuropsychiatric interventions. These results are valuable for healthcare planning because the current practice in countries of these regions does not match well with the economic evidence. A high proportion of mental health budgets are currently being used in the provision of the least cost effective interventions (such as long term inpatient treatment of severe mental disorders), ${ }^{2}$ and little is invested in more cost effective strategies (including the community based provision of adjuvant psychosocial treatment for severe mental disorders or measures to reduce access to or marketing of alcohol).

\section{From regional to national evaluation}

In addition to political barriers, ${ }^{23}$ the existence of cost effectiveness information at the aggregate level of WHO sub-regions is no guarantee that findings and recommendations will actually change health policy at the national level (where policies are determined and resources allocated). Accordingly, there is a need to contextualise regional estimates to the country level, since many factors may influence the actual cost effectiveness of a given intervention across settings; such a process has now been undertaken in several WHO member states, including Estonia, Mexico, Nigeria, Spain, Sri Lanka, and Thailand. ${ }^{1924-26}$ Results from this process of country contextualisation have shown a high degree of agreement with regional rankings of cost effectiveness, but differences in the absolute cost or specific effect of certain interventions (for example, because of locally applicable drug price tariffs in Nigeria or rates of heavy alcohol use in Thailand that were higher than the regional average).

More broadly, there is a need to translate research into practice and policies into action. WHO's mental health Gap Action Programme has been designed to do just that and is assisting countries to scale up service provision in order to reduce the substantial treatment gap that exists in so many low income countries. ${ }^{4}$ The financial cost of scaling up the provision of a set of mental healthcare interventions in low income countries has been estimated to be about US\$2 (\$Int3) per capita per year. ${ }^{27}$ However, this estimate did not include epilepsy treatment or population based alcohol control measures, and used a lower target coverage level for depression. For the target coverage levels and fuller intervention set specified here, an updated estimate would be US\$3.25-3.80 (\$Int4.90-5.70).

\section{Study limits and limitations}

The process of contextualisation down to the level of individual countries represents an important test and validation of the model and results developed by WHO-CHOICE, but modelling exercises of this kind still have limitations, whatever the geographical or resource setting. In particular, many of the epidemiological and efficacy input values used were international estimates: the empirical basis for estimates of the use, cost, outcome, and impact of services for people with neuropsychiatric conditions at the national level needs to be improved, particularly for interventions with a substantial behavioural element (such as the effect of psychosocial treatment or the impact of restricting the marketing of and access to alcohol).

The outcome of interest in cost effectiveness analyses of this kind is the improvement of a population's health, as opposed to "non-health" attributes of social welfare (including improved productivity). Inclusion of the impact of interventions on income, employment, or poverty, for example, would strengthen the economic rationale for scaling up services. ${ }^{28}$ In the case of demand reduction measures for alcohol—which has been described as "no ordinary commodity" — consideration of the various welfare consequences is complicated, since the health and other benefits of their implementation (such as reduced crime) would need to be viewed in light of higher prices or greater restrictions on consumers and other economic operators. As such, the economic evidence presented here provides but one of several inputs into decision making and resource allocation.

\section{Setting priorities for neuropsychiatric conditions}

For the broader task of priority setting, there is a need to go beyond economic concerns only. Other criteria that need to be considered include the relative severity and extent of spillover effects among different diseases, the potential for reducing catastrophic household spending on health, and protection of human rights. ${ }^{26}$ Priority setting necessarily implies a degree of trade-off between different objectives of the mental health system. Schizophrenia treatment, for example, risks being overlooked on pure efficiency grounds in favour of more cost effective strategies for more common mental disorders. However, schizophrenia remains a priority condition for the WHO and others ${ }^{5}$ because of its severity, the risk of affected people to be exposed to severe human rights violations, and its often catastrophic effect on the welfare and income of family members. Research into the economic and social consequences of neuropsychiatric disorders on households is particularly needed in resource constrained settings where health insurance coverage is low, and amelioration of these adverse impacts through appropriate intervention can only enhance the value or worth of the strategies highlighted here.

We thank Dr Mark van Ommeren for helpful comments on an earlier draft of this manuscript.

Contributors: DC designed the study, undertook the analysis, and drafted the paper. SS participated in the study design and interpretation of results and provided comments on the draft. DC is guarantor for the validity of the study results.

Funding: No external funding or sponsorship.

Competing interests: All authors have completed the ICMJE uniform disclosure form at www.icmje.org/coi_disclosure.pdf (available on request from the corresponding author) and declare: no support from any organisation for the submitted work; no financial relationships with any organisations that might have an interest in the submitted work in the previous three years; no other relationships or activities that could appear to have influenced the submitted work.

The authors are staff members of the WHO. The authors alone are responsible for the views expressed in this publication and they do not necessarily represent the decisions, policy, or views of the WHO.

Ethical approval: Not required.

Data sharing: No additional data available 


\section{What is already known on this topic}

Neuropsychiatric problems impose a substantial clinical, social, and economic burden on different regions of the world

Economic analysis for a subset of neuropsychiatric conditions has identified interventions that are expected to be cost effective for combating neuropsychiatric problems in low and middle income countries

\section{What this study adds}

Simultaneous evaluation of the cost effectiveness of 44 individual or combined interventions for five key neuropsychiatric conditions identified those that-from an efficiency perspective-have the most claim on resources for mental health in sub-Saharan Africa and South East Asia

Alcohol control measures and drug treatment for epilepsy and depression were found to offer the best value for money

The cost per capita of a scaled up, combined package covering all assessed conditions is estimated to be US\$3.25-3.80 (\$Int4.90-5.70). This package comprises the prevention or treatment of epilepsy (with older antiepileptic drugs); depression (with generic newer antidepressant drugs and psychosocial treatment); bipolar disorder (with the mood-stabiliser lithium); schizophrenia (with neuroleptic antipsychotic drugs and psychosocial treatment); and heavy alcohol use (via increased taxation and reduced accesses to alcohol and, in the African sub-region, advertising bans and brief advice to heavy drinkers in primary care)

1 Saxena S, Thornicroft G, Knapp M, Whiteford H. Resources for mental health: scarcity, inequity and inefficiency. Lancet 2007:370:878-89.

2 Jacob KS, Sharan P, Mirzal, Garrido-Cumbrera M, Seedat S, Mari JJ, et al. Mental health systems in countries: where are we now? Lancet 2007;370:1061-77.

3 Mbuba CK, Ngugi AK, Newton CR, Carter JA. The epilepsy treatment gap in developing countries: a systematic review of the magnitude, causes, and intervention strategies. Epilepsia 2008;49:1491-503.

4 Demyttenaere K, Bruffaerts R, Posada-Villa J, Gasquet I, Kovess V, Lepine JP, et al. Prevalence, severity, and unmet need for treatment of mental disorders in the World Health Organization World Mental Health Surveys. JAMA 2004;291:2581-90.

5 World Health Organization. mhGAP: Mental Health Gap Action Programme: scaling up care for mental, neurological and substance use disorders. WHO, 2008.

6 World Health Organization. The global burden of disease: 2004 update. WHO, 2008.

7 Rehm J, Room R, Monteiro M, Gmel G, Graham K, Rehn T, et al. Alcohol. In: World Health Organization. Comparative quantification of health risks: global and regional burden of disease due to selected major risk factors. WHO, 2004.

8 Nathan PE, Gorman JM. A guide to treatments that work. 2nd ed. Oxford University Press, 2002.

9 Babor T, Caetano R, Casswell S, Edwards G. Alcohol: no ordinary commodity-a consumer's guide to public policy. Oxford University Press, 2003.

10 Engel J, Pedley TA. Epilepsy: a comprehensive textbook . Lippincott-Raven, 1997.

11 World Health Organization. mhGAP intervention guide for mental, neurological and substance use disorders in non-specialised settings. WHO, 2010.

12 World Health Organization. Global strategy to reduce the harmful use of alcohol. WHO 2010.

13 Evans DB, Edejer TT, Adam T, Lim SS. Methods to assess the costs and health effects of interventions for improving health in developing countries. BMJ 2005:331:1137-40.

14 Tan Torres T, Baltussen RM, Adam T, Acharya T, Evans D. Making choices in health: WHO guide to cost-effectiveness analysis. WHO, 2003.

15 Chisholm D. Cost-effectiveness of first-line anti-epileptic drug treatments in the developing world: a population-level analysis. Epilepsia 2005;46:751-9.

16 Chisholm D, Sanderson K, Ayuso-Mateos JL, Saxena S. Reducing the burden of depression: a population-level analysis of intervention cost-effectiveness in 14 epidemiologically-defined sub-regions (WHO-CHOICE). Br J Psychiatry 2004;184:393-403.

17 Chisholm D, Rehm J, van Ommeren M, Monteiro M, on behalf of WHO-CHOICE. Reducing the global burden of heavy alcohol use: a comparative cost-effectiveness analysis. J Stud Alcohol 2004;65:782-93.
18 Chisholm D, van Ommeren M, Ayuso-Mateos JL, Saxena S. Cost-effectiveness of clinical interventions for reducing the global burden of bipolar disorder: a global analysis (WHO-CHOICE). Br J Psychiatry 2005;187:559-67.

19 Chisholm D, Gureje O, Saldivia S, Villalón Calderón M, Wickremasinghe R, Mendis N, et al. Schizophrenia treatment in the developing world: an inter-regional and multi-national cost-effectiveness analysis. Bull World Health Organ 2008;86:542-51.

20 Sabate E. Adherence to long-term therapies: evidence for action. WHO, 2003.

21 Ferri C, Chisholm D, van Ommeren M, Prince M. Resource utilisation for neuropsychiatric disorders in developing countries: a multinational Delphi consensus study. Soc Psychiatry Psychiatr Epidemiol 2004;39:218-27.

22 Chisholm D, Baltussen R, Evans DB, Ginsberg G, Lauer J, Lim S, et al. What are the priorities for prevention and control of non-communicable diseases and injuries in sub-Saharan Africa and South East Asia? BMJ 2012;344:e586.

23 Saraceno B, van Ommeren M, Batniji R, Cohen A, Gureje O, Mahoney J, et al. Barriers to improvement of mental health services in low-income and middle-income countries. Lancet 2007;370:1164-74

24 Gureje O, Chisholm D, Kola L, Lasebikan V, Saxena S. Cost-effectiveness of an essential mental health intervention package in Nigeria. World Psychiatry 2007;6:42-8.

25 Salomon JA, Carvalho N, Gutiérrez-Delgado C, Casey A, Hogan DR, Lee D, et al. Intervention strategies to reduce the burden of non-communicable diseases in Mexico: cost effectiveness analysis. BMJ 2012;344:e355.

26 World Health Organization. Dollars, DALYs and decisions: economic aspects of the mental health system. WHO, 2006

27 Chisholm D, Lund C, Saxena S. Cost of scaling up mental healthcare in low- and middle-income countries. Br J Psychiatry 2007;191:528-35.

28 Lund C, de Silva M, Plagerson S, Cooper S, Chisholm D, Das V, et al. Poverty and mental disorders: breaking the cycle in low-income and middle-income countries. Lancet 2011:378:1502-14.

\section{Accepted: 10 October 2011}

\section{Cite this as: BMJ 2012;344:e609}

This is an open-access article distributed under the terms of the Creative Commons Attribution Non-commercial License, which permits use, distribution, and reproduction in any medium, provided the original work is properly cited, the use is non commercial and is otherwise in compliance with the license. See: http://creativecommons.org/licenses/by$\mathrm{nc} / 2.0 /$ and http://creativecommons.org/licenses/by-nc/2.0/legalcode. 


\section{Tables}

\section{Table 1 | Assessed interventions for mental, neurological, and substance use conditions}

\begin{tabular}{|c|c|c|c|c|}
\hline Condition & Setting(s) & Target coverage & Interventions & Efficacy $(\% \text { change })^{*}$ \\
\hline Schizophrenia & $\begin{array}{l}\text { Hospital inpatient } v \\
\text { hospital outpatient }\end{array}$ & $80 \%$ & $\begin{array}{l}\text { Older antipsychotic drugs (such as haloperidol) versus newer } \\
\text { antipsychotics (such as risperidone), with or without adjuvant } \\
\text { psychosocial treatment (such as family psycho-education) }\end{array}$ & $-15 \%$ to $-30 \%$ (disability weight) \\
\hline Bipolar disorder & $\begin{array}{l}\text { Hospital inpatient } v \\
\text { hospital outpatient }\end{array}$ & $50 \%$ & $\begin{array}{l}\text { Mood stabiliser drug (lithium carbonate) versus } \\
\text { anticonvulsants (such as sodium valproate), with or without } \\
\text { adjuvant psychosocial treatment (such as family } \\
\text { psycho-education) }\end{array}$ & $\begin{array}{l}-50 \% \text { to }-53 \% \text { (disability weight) } \\
-65 \% \text { (case fatality, for lithium only) }\end{array}$ \\
\hline \multirow[t]{3}{*}{ Depression } & \multirow[t]{3}{*}{ Primary health care } & \multirow[t]{3}{*}{$50 \%$} & $\begin{array}{l}\text { Older (tricyclic) antidepressant drugs (such as amitriptyline) } \\
\text { versus newer antidepressants (generic SSRI such as } \\
\text { fluoxetine) }\end{array}$ & \multirow[t]{3}{*}{$\begin{array}{l}25 \% \text { to } 40 \% \text { (remission); }-25 \% \\
\text { (disability weight); }-50 \% \\
\text { (recurrence, for proactive care only) }\end{array}$} \\
\hline & & & Psychosocial treatment, alone or with drugs & \\
\hline & & & $\begin{array}{l}\text { Proactive maintenance treatment for recurrent cases (at } \\
\text { least two lifetime episodes of depression) }\end{array}$ & \\
\hline Epilepsy & Primary health care & $80 \%$ & $\begin{array}{l}\text { Older, first line antiepileptic drugs (such as phenobarbitone, } \\
\text { phenytoin) versus newer antiepileptics (such as } \\
\text { carbamazepine, valproic acid) }\end{array}$ & $\begin{array}{l}60 \% \text { (remission); }-43 \% \text { (disability } \\
\text { weight) }\end{array}$ \\
\hline \multirow[t]{4}{*}{ Heavy alcohol use } & Primary health care & $30 \%$ & Brief physician advice & $\begin{array}{l}14 \% \text { to } 18 \% \text { (remission); }-5.5 \% \\
\text { (disability weight) }\end{array}$ \\
\hline & \multirow[t]{3}{*}{ Population based } & \multirow[t]{3}{*}{$95 \%$} & Excise tax (current plus $20-50 \%$ increase) & \multirow{3}{*}{$\begin{array}{l}-4.4 \% \text { to }-7.7 \% \text { (incidence, for tax) } \\
-2.5 \% \text { to }-3.0 \% \text { (incidence, for } \\
\text { advertising bans or reduced } \\
\text { access); }-3 \% \text { to }-4 \% \text { (alcohol } \\
\text { related traffic fatality, for reduced } \\
\text { access only) }\end{array}$} \\
\hline & & & Advertising bans (comprehensive) & \\
\hline & & & Reduced retail access (reduced opening hours) & \\
\hline
\end{tabular}

$\mathrm{SSRI}=$ selective serotonin reuptake inhibitor.

*Improvement relative to the situation of no intervention; not adjusted for population-level effect modifiers (coverage, response, adherence). 
Table 2/ Costs, effects, and cost effectiveness of interventions to combat mental, neurological, and substance use conditions in WHO sub-Saharan African sub-region AfrE and South East Asian sub-region SearD

\begin{tabular}{|c|c|c|c|c|c|c|c|c|}
\hline \multirow[b]{3}{*}{ Intervention } & \multicolumn{4}{|c|}{ WHO African sub-region AfrE } & \multicolumn{4}{|c|}{ WHO Asian sub-region SearD } \\
\hline & \multirow{2}{*}{$\begin{array}{l}\text { Annual } \\
\text { cost per } \\
\text { capita } \\
\text { (\$Int) }\end{array}$} & \multirow{2}{*}{$\begin{array}{l}\text { Annual } \\
\text { DALYs } \\
\text { saved per } \\
\text { million } \\
\text { population }\end{array}$} & \multicolumn{2}{|c|}{ Cost effectiveness ratio } & \multirow{2}{*}{$\begin{array}{l}\text { Annual } \\
\text { cost per } \\
\text { capita } \\
\text { (\$Int) }\end{array}$} & \multirow{2}{*}{$\begin{array}{l}\text { Annual } \\
\text { DALYs } \\
\text { saved per } \\
\text { million } \\
\text { population }\end{array}$} & \multicolumn{2}{|c|}{ Cost effectiveness ratio } \\
\hline & & & Average* $^{*}$ & Incremental† & & & Average* & Incremental† \\
\hline \multicolumn{9}{|c|}{ Schizophrenia (all interventions at $80 \%$ coverage) } \\
\hline $\begin{array}{l}\text { SCZ-1: Older antipsychotic drug } \\
\text { (community model) }\end{array}$ & 0.84 & 159 & 5276 & Dominated $\ddagger$ & 0.81 & 174 & 4657 & Dominated $\ddagger$ \\
\hline $\begin{array}{l}\text { SCZ-2: Newer antipsychotic drug } \\
\text { (community model) }\end{array}$ & 2.84 & 193 & 14749 & Dominated $\neq$ & 3.16 & 210 & 15046 & Dominated $\ddagger$ \\
\hline $\begin{array}{l}\text { SCZ-3: Older antipsychotic + } \\
\text { psychosocial treatment (community } \\
\text { model) }\end{array}$ & 0.91 & 332 & 2748 & 2748 & 0.86 & 363 & 2375 & 2375 \\
\hline $\begin{array}{l}\text { SCZ-4: Newer antipsychotic + } \\
\text { psychosocial treatment (community } \\
\text { model) }\end{array}$ & 2.94 & 388 & 7585 & 36504 & 3.24 & 423 & 7663 & 39285 \\
\hline $\begin{array}{l}\text { SCZ-5: Older antipsychotic (hospital } \\
\text { model) }\end{array}$ & 2.59 & 159 & 16282 & Dominated $\neq$ & 2.66 & 174 & 15281 & Dominated $\neq$ \\
\hline $\begin{array}{l}\text { SCZ-6: Newer antipsychotic (hospital } \\
\text { model) }\end{array}$ & 4.59 & 193 & 23852 & Dominated $\neq$ & 5.01 & 210 & 23833 & Dominated $\neq$ \\
\hline $\begin{array}{l}\text { SCZ-7: Older antipsychotic + } \\
\text { psychosocial treatment (hospital model) }\end{array}$ & 2.26 & 332 & 6816 & Dominated $\ddagger$ & 2.31 & 363 & 6365 & Dominated $\neq$ \\
\hline $\begin{array}{l}\text { SCZ-8: Newer antipsychotic }+ \\
\text { psychosocial treatment (hospital model) }\end{array}$ & 4.29 & 388 & 11072 & Dominated $\neq$ & 4.69 & 423 & 11085 & Dominatedł \\
\hline \multicolumn{9}{|c|}{ Bipolar disorder (all interventions at $50 \%$ coverage) } \\
\hline $\begin{array}{l}\text { BIP-1: Older mood stabiliser (lithium) } \\
\text { (community model) }\end{array}$ & 0.62 & 347 & 1800 & 1800 & 0.71 & 357 & 2001 & 2001 \\
\hline $\begin{array}{l}\text { BIP-2: Older mood stabiliser + } \\
\text { psychosocial care (community model) }\end{array}$ & 0.98 & 382 & 2551 & 9916 & 1.20 & 392 & 3048 & 13444 \\
\hline $\begin{array}{l}\text { BIP-3: Newer mood stabiliser (valproate) } \\
\text { (community model) }\end{array}$ & 0.86 & 248 & 3448 & Dominatedł & 1.01 & 322 & 3145 & Dominated $\neq$ \\
\hline $\begin{array}{l}\text { BIP-4: Newer mood stabiliser + } \\
\text { psychosocial care (community model) }\end{array}$ & 1.20 & 273 & 4387 & Dominated $\ddagger$ & 1.49 & 354 & 4210 & Dominatedł \\
\hline $\begin{array}{l}\text { BIP-5: Older mood stabiliser (hospital } \\
\text { model) }\end{array}$ & 1.62 & 347 & 4678 & Dominated $\neq$ & 1.95 & 357 & 5483 & Dominatedł \\
\hline $\begin{array}{l}\text { BIP-6: Older mood stabiliser + } \\
\text { psychosocial care (hospital model) }\end{array}$ & 1.86 & 382 & 4874 & Dominated $\neq$ & 2.30 & 392 & 5864 & Dominated $\ddagger$ \\
\hline $\begin{array}{l}\text { BIP-7: Newer mood stabiliser drug } \\
\text { (hospital model) }\end{array}$ & 1.71 & 248 & 6864 & Dominated $\neq$ & 2.08 & 322 & 6476 & Dominated $\ddagger$ \\
\hline $\begin{array}{l}\text { BIP-8: Newer mood stabiliser + } \\
\text { psychosocial care (hospital model) }\end{array}$ & 1.95 & 273 & 7152 & Dominated $\neq$ & 2.45 & 354 & 6913 & Dominatedł \\
\hline \multicolumn{9}{|c|}{ Depression (all interventions at $50 \%$ coverage) } \\
\hline $\begin{array}{l}\text { DEP-1: Episodic treatment with older } \\
\text { antidepressants (TCAs) }\end{array}$ & 0.63 & 610 & 1029 & Dominated $\neq$ & 0.90 & 984 & 916 & Dominated $\ddagger$ \\
\hline $\begin{array}{l}\text { DEP-2: Episodic treatment with newer } \\
\text { antidepressants (SSRIs) }\end{array}$ & 0.58 & 681 & 858 & 858 & 0.83 & 1098 & 756 & 756 \\
\hline DEP-3: Episodic psychosocial treatment & 2.19 & 679 & 3225 & Dominated $\ddagger$ & 3.24 & 1095 & 2957 & Dominated $\neq$ \\
\hline $\begin{array}{l}\text { DEP-4: Episodic psychosocial treatment } \\
\text { + older antidepressants }\end{array}$ & 2.10 & 797 & 2641 & Dominated $\neq$ & 3.11 & 1285 & 2416 & Dominated $\neq$ \\
\hline $\begin{array}{l}\text { DEP-5: Episodic psychosocial treatment } \\
+ \text { newer antidepressants }\end{array}$ & 2.06 & 875 & 2356 & Dominated $\neq$ & 3.04 & 1412 & 2151 & Dominated $\neq$ \\
\hline $\begin{array}{l}\text { DEP-6: Maintenance psychosocial } \\
\text { treatment + older antidepressants }\end{array}$ & 2.12 & 1452 & 1456 & Dominated $\ddagger$ & 3.05 & 2343 & 1300 & Dominated $\neq$ \\
\hline $\begin{array}{l}\text { DEP-7: Maintenance psychosocial } \\
\text { treatment + newer antidepressants }\end{array}$ & 2.02 & 1526 & 1326 & 1704 & 2.90 & 2463 & 1178 & 1517 \\
\hline
\end{tabular}


Table 2 (continued)

\begin{tabular}{|c|c|c|c|c|c|c|c|c|}
\hline \multirow[b]{3}{*}{ Intervention } & \multicolumn{4}{|c|}{ WHO African sub-region AfrE } & \multicolumn{4}{|c|}{ WHO Asian sub-region SearD } \\
\hline & \multirow{2}{*}{$\begin{array}{l}\text { Annual } \\
\text { cost per } \\
\text { capita } \\
\text { (\$Int) }\end{array}$} & \multirow{2}{*}{$\begin{array}{l}\text { Annual } \\
\text { DALYs } \\
\text { saved per } \\
\text { million } \\
\text { population }\end{array}$} & \multicolumn{2}{|c|}{ Cost effectiveness ratio } & \multirow{2}{*}{$\begin{array}{l}\text { Annual } \\
\text { cost per } \\
\text { capita } \\
\text { (\$Int) }\end{array}$} & \multirow{2}{*}{$\begin{array}{l}\text { Annual } \\
\text { DALYs } \\
\text { saved per } \\
\text { million } \\
\text { population }\end{array}$} & \multicolumn{2}{|c|}{ Cost effectiveness ratio } \\
\hline & & & Average* $^{\star}$ & Incremental† & & & Average* & Incremental† \\
\hline \multicolumn{9}{|l|}{ Epilepsy } \\
\hline $\begin{array}{l}\text { EPI-1: Older antiepileptic drug in primary } \\
\text { care at } 50 \% \text { coverage }\end{array}$ & 0.36 & 1360 & 265 & 265 & 0.15 & 519 & 286 & 286 \\
\hline $\begin{array}{l}\text { EPI-2: Older antiepileptic in primary care } \\
\text { at } 80 \% \text { coverage }\end{array}$ & 0.63 & 2176 & 288 & 325 & 0.24 & 830 & 292 & 300 \\
\hline $\begin{array}{l}\text { EPI-3: Newer antiepileptic in primary care } \\
\text { at } 50 \% \text { coverage }\end{array}$ & 0.63 & 1360 & 465 & Dominated $\neq$ & 0.27 & 519 & 518 & Dominated $\ddagger$ \\
\hline $\begin{array}{l}\text { EPI- } 4 \text { : Newer antiepileptic in primary care } \\
\text { at } 80 \% \text { coverage }\end{array}$ & 1.06 & 2176 & 488 & Dominated $\ddagger$ & 0.43 & 830 & 524 & Dominated $\neq$ \\
\hline \multicolumn{9}{|l|}{ Heavy alcohol use } \\
\hline ALC-1: Current taxation & 0.23 & 1794 & 128 & Dominated $\ddagger$ & 0.13 & 69 & 1821 & Dominated $\neq$ \\
\hline $\begin{array}{l}\text { ALC-2: Increased taxation (current + } \\
20 \% \text { ) }\end{array}$ & 0.23 & 1812 & 127 & Dominated $\ddagger$ & 0.13 & 75 & 1666 & Dominated $\neq$ \\
\hline $\begin{array}{l}\text { ALC-3: Increased taxation (current + } \\
50 \% \text { ) }\end{array}$ & 0.23 & 1963 & 117 & 117 & 0.13 & 86 & 1462 & 1462 \\
\hline $\begin{array}{l}\text { ALC-4: Reduced untaxed consumption } \\
\text { (current }-20 \% \text { ) }\end{array}$ & 0.40 & 2183 & 183 & Dominated $\ddagger$ & 0.24 & 75 & 3281 & Dominated $\neq$ \\
\hline $\begin{array}{l}\text { ALC-5: Reduced untaxed consumption } \\
\text { (current }-50 \% \text { ) }\end{array}$ & 0.45 & 2768 & 164 & Dominated $\neq$ & 0.29 & 83 & 3454 & Dominated $\neq$ \\
\hline $\begin{array}{l}\text { ALC- } 6 \text { : Reduced access to retail outlets } \\
(80 \% \text { coverage })\end{array}$ & 0.17 & 799 & 212 & Dominated $\ddagger$ & 0.09 & 56 & 1677 & Dominated $\neq$ \\
\hline $\begin{array}{l}\text { ALC- } 7 \text { : Comprehensive advertising ban } \\
(80 \% \text { coverage })\end{array}$ & 0.17 & 562 & 301 & Dominated $\ddagger$ & 0.09 & 30 & 3146 & Dominated $\neq$ \\
\hline $\begin{array}{l}\text { ALC-8: Brief advice in primary care }(30 \% \\
\text { coverage) }\end{array}$ & 0.38 & 461 & 822 & Dominated $\ddagger$ & 0.11 & 29 & 3837 & Dominated $\neq$ \\
\hline $\begin{array}{l}\text { ALC-9: Increased tax + scaled up tax } \\
\text { enforcement }\end{array}$ & 0.61 & 4494 & 137 & 152 & 0.37 & 160 & 2316 & Dominated‡ \\
\hline ALC-10: Increased tax + reduced access & 0.38 & 2706 & 140 & Dominated $\ddagger$ & 0.21 & 139 & 1500 & 1560 \\
\hline ALC-11: Increased tax + advertising ban & 0.38 & 2475 & 153 & Dominated $\ddagger$ & 0.21 & 113 & 1839 & Dominated $\ddagger$ \\
\hline ALC-12: Increased tax + brief advice & 0.60 & 2375 & 251 & Dominated $\ddagger$ & 0.23 & 113 & 2070 & Dominated $\neq$ \\
\hline $\begin{array}{l}\text { ALC-13: Increased tax + advertising ban } \\
+ \text { brief advice }\end{array}$ & 0.74 & 2896 & 255 & Dominated $\neq$ & 0.32 & 140 & 2244 & Dominated $\ddagger$ \\
\hline $\begin{array}{l}\text { ALC-14: Increased tax + advertising ban } \\
+ \text { reduced access }\end{array}$ & 0.54 & 3224 & 167 & Dominated & 0.30 & 166 & 1788 & 3240 \\
\hline $\begin{array}{l}\text { ALC-15: Increased tax + reduced access } \\
+ \text { tax enforcement }\end{array}$ & 0.81 & 5363 & 151 & 224 & 0.48 & 218 & 2207 & 3550 \\
\hline $\begin{array}{l}\text { ALC-16: Increased tax }+ \text { brief advice + } \\
\text { advertising ban }+ \text { reduced access }\end{array}$ & 0.90 & 3595 & 250 & Dominated $\ddagger$ & 0.40 & 191 & 2120 & Dominatedł \\
\hline $\begin{array}{l}\text { ALC-17: Increased tax }+ \text { brief advice }+ \\
\text { advertising ban }+ \text { reduced access }+ \text { tax } \\
\text { enforcement }\end{array}$ & 1.33 & 6028 & 220 & 783 & 0.68 & 261 & 2593 & 4539 \\
\hline
\end{tabular}

DALYs=disability adjusted life years. \$Int=international dollars. TCA=tricyclic antidepressants. SSRI=selective serotonin reuptake inhibitor.

*\$Int per DALY averted relative to no intervention.

†\$Int per DALY averted, within intervention cluster

łIntervention is more costly or less effective than other more efficient interventions, and results are therefore not included here. 


\section{Figures}

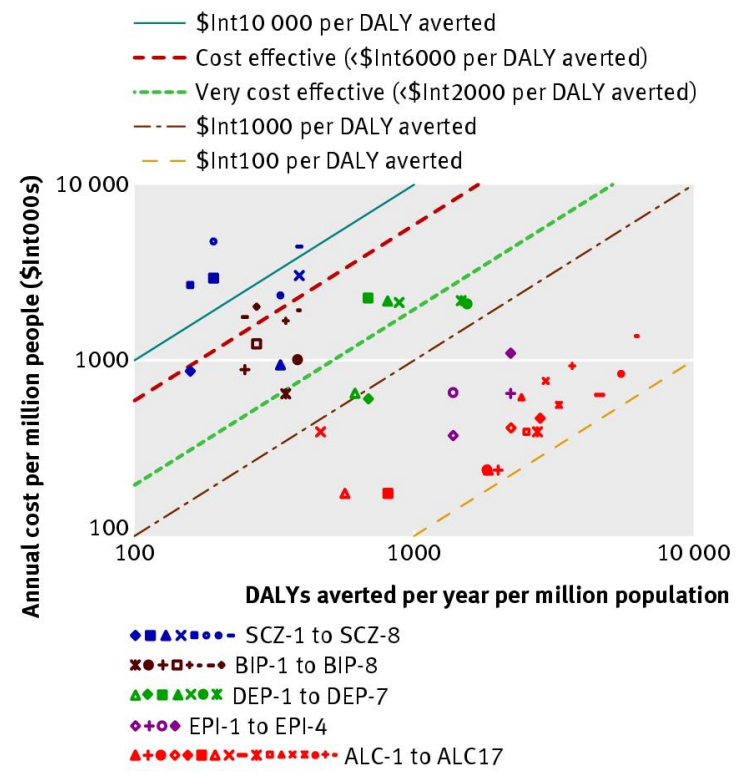

Fig 1 Comparative cost per DALY averted for selected interventions to combat neuropsychiatric conditions in sub-Saharan African sub-region AfrE. See table $2 \Downarrow$ for explanation of intervention codes

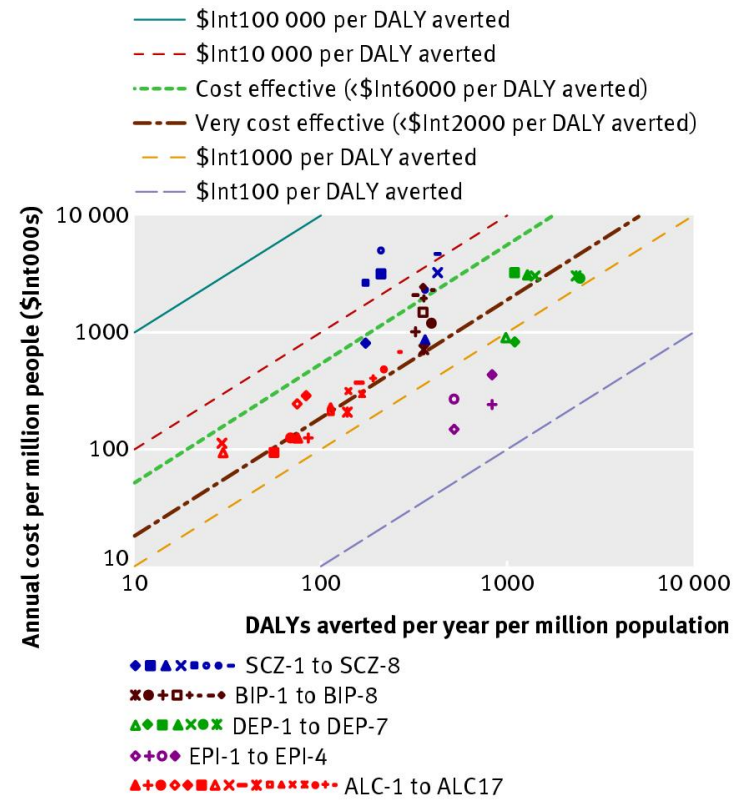

Fig 2 Comparative cost per DALY averted for selected interventions to combat neuropsychiatric conditions in South East Asian sub-region SearD. See table $2 \Downarrow$ for explanation of intervention codes 


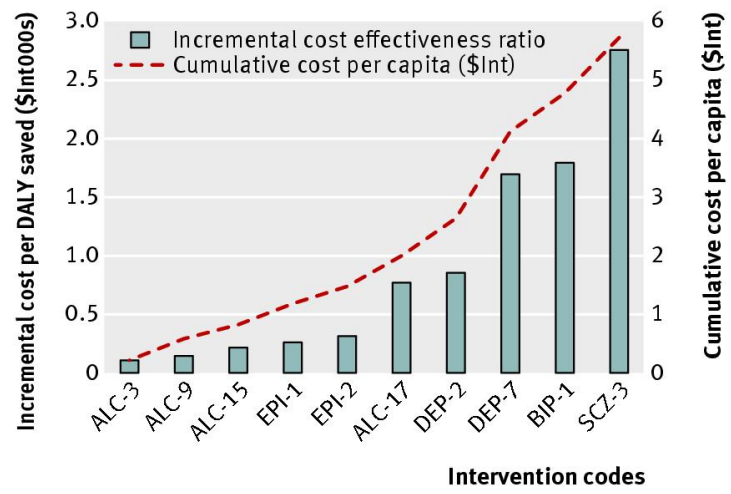

Fig 3 Cost effectiveness of non-dominated interventions to combat neuropsychiatric conditions in sub-Saharan African sub-region AfrE and cumulative cost per capita. See table $2 \Downarrow$ for explanation of intervention codes

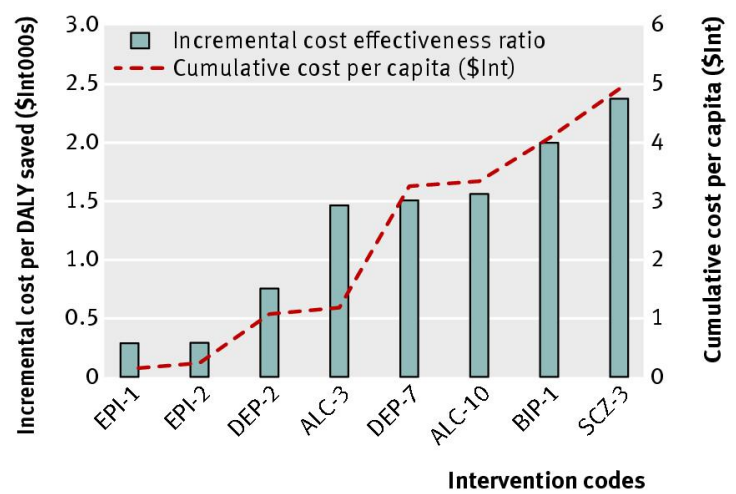

Fig 4 Cost effectiveness of non-dominated interventions to combat neuropsychiatric conditions in South East Asian sub-region SearD and cumulative cost per capita. See table $2 \Downarrow$ for explanation of intervention codes 